\title{
Tensile, Flexural, and Morphological Properties of Jute/Oil Palm Pressed Fruit Fibers Reinforced High Density Polyethylene Hybrid Composites
}

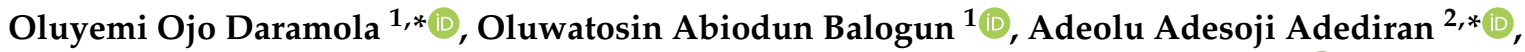 \\ Sheriff Olalekan Saka ${ }^{1}$, Isiaka Oluwole Oladele ${ }^{1}$ and Esther Titilayo Akinlabi ${ }^{3,4}{ }^{(1)}$ \\ 1 Department of Metallurgical and Materials Engineering, Federal University of Technology, \\ Akure 340001, Nigeria; tobalogs39@gmail.com (O.A.B.); sheriffsaka@gmail.com (S.O.S.); \\ wolesuccess2000@yahoo.com (I.O.O.) \\ 2 Department of Mechanical Engineering, Landmark University, Omu-Aran, PMB 1001, \\ Omu-Aran 251101, Nigeria \\ 3 Directorate, Pan African University of Life Sciences Institute, Ibadan 110115, Nigeria; etakinlabi@gmail.com \\ 4 Department of Mechanical Science, Auckland Park Campus, University of Johannesburg, \\ Johannesburg 2006, South Africa \\ * Correspondence: oodaramola@futa.edu.ng (O.O.D.); adediran.adeolu@lmu.edu.ng (A.A.A.); \\ Tel.: +234-816-681-4002 (O.O.D.)
}

check for updates

Citation: Daramola, O.O.; Balogun, O.A.; Adediran, A.A.; Saka, S.O.; Oladele, I.O.; Akinlabi, E.T. Tensile, Flexural, and Morphological Properties of Jute/Oil Palm Pressed Fruit Fibers Reinforced High Density Polyethylene Hybrid Composites. Fibers 2021, 9, 71. https:/ /doi.org/ 10.3390/fib9110071

Academic Editor: Vincenzo Fiore

Received: 11 February 2021

Accepted: 31 August 2021

Published: 2 November 2021

Publisher's Note: MDPI stays neutral with regard to jurisdictional claims in published maps and institutional affiliations.

Copyright: (c) 2021 by the authors. Licensee MDPI, Basel, Switzerland. This article is an open access article distributed under the terms and conditions of the Creative Commons Attribution (CC BY) license (https:// creativecommons.org/licenses/by/ $4.0 /)$.
Abstract: The incorporation of materials that were formally regarded as agricultural wastes into polymeric matrix has drawn the attention of many researchers in recent years. This research focused on reinforcing high-density polyethylene (HDPE) matrix with treated jute fiber (JF)/oil palm pressed fruit fibers (OPPFF) at varying weight proportions. JF and OPPFF were cut to $2.5 \mathrm{~mm}$ length and were chemically treated thereafter with $1 \mathrm{M}$ and $1.5 \mathrm{M}$ sodium hydroxide solution respectively. The composites were produced using the compression molding technique. The morphological characterization of the fibers and composites for untreated and treated samples was studied with the aid of a scanning electron microscope (SEM). Tensile and flexural properties of the produced composite samples were also determined. From the result, the surface morphology of the fiber after treatment showed that there was obvious exposure of the fiber surface and removal of impurities as this influenced the microstructure of the composites and in turn the tensile and flexural properties. Hence, it was observed that $20 \mathrm{wt}$.\% treated jute fiber addition shows the most significant enhancements in terms of tensile and flexural properties. The study exposed the effect of surface modification of JF/OPPF hybridization on HDPE matrix composite.

Keywords: high-density polyethylene; fibers; composites; tensile; morphology; flexural properties

\section{Introduction}

The improvements in technology over the years have led to the constant need for materials with improved properties for high-performance applications such as aerospace, structural, automobile, and marine applications. These applications employ the use of composite materials [1,2]. A composite is the combination of two or more engineering materials of clearly distinct properties, to combine their attractive properties while neglecting their drawbacks. The composite is largely made up of two phases: the matrix phase and the reinforcement phase [3]. However, the polymeric matrix can be classified as thermoplastics (include high and low densities polyethylene, polyvinyl chloride, polypropylene, and polyethylene Terephthalate) and thermoset (epoxy, polyester, and vinyl ester) polymers [4,5]. Likewise, reinforcing materials such as Kevlar, glass fiber, and carbon fiber had also been used in producing composites in the past, these materials improved the properties of the matrix, but they are detrimental to human health and the environment at large. For this reason, the attention of researchers has been drawn to the use of natural 
fibers for the production of environmentally friendly and ecoefficient materials. Natural fibers are non-toxic, they are renewable when used in composite production, available in abundance, and they improve service life and performance while reducing energy and service intensity $[4,6]$. Natural fibers such as jute, bamboo, coir, cotton, dombeya butneri, hemp, and oil palm fibers have been used as reinforcements in recent research but these fibers are hydrophilic which has been their main drawback [7-9]. They readily absorb moisture leading to poor interfacial adhesion between the matrix material and the reinforcements used. This problem can lead to poor mechanical and wear properties of the composite. Therefore, there is a need to modify the hydrophilic nature of these fibers. Researchers have recently employed various chemical treatments such as silane treatment, benzoylation, acrylation, and alkali treatment. However, for this study, alkali treatment was employed for the treatment of the fibers. This is because the treatments have been reported to improve the interfacial adhesion between the fibers and the matrix $[7,8]$. Fiber like Jute is a bast fiber that possesses good mechanical properties that is comparable to that of glass fiber [10]. They are used for producing bags and ropes and their properties can vary based on their origin and location. When jute fibers are used as reinforcement they act as the main load-carrying components being held together by the matrix [11]. Meanwhile, oil palm pressed fruit (OPPF) fiber is a product from oil palm (Elaeis guineensis), which is regarded as an agricultural waste that is available in abundance. According to [12], the production of palm oil throughout the world is increasing yearly. For instance, in $2012 / 2013,56.38$ million metric tons of palm oil was produced compared to 75.45 million metric tons recorded in 2020/2021. This seems to suggest that oil palm byproduct produced has also increased over the years which provokes more problems regarding how to dispose of waste generated during palm oil production. Instead of burning or dumping oil palm biomass in landfills, they can be renewed as reinforcement in the polymer matrix. Through this, oil palm byproducts can be given economic value by making them useful in various engineering applications. Past research has explored the possibility of using natural fibers as reinforcement to improve the mechanical, physical, and thermal properties of the polymer. In a bid to enhance sustainability, a study by [13] developed polymer composite using 50\% recycled HDPE $/ 50 \%$ virgin HDPE and matrix material. Jute fiber was used as reinforcement at a proportion of 10-30 wt.\% by weight of the matrix, their result revealed that tensile strength reduced from $3.4-24.3 \%$ while flexural strength appreciated by $4-8.6 \%$ as the fiber content increased from 10-30 wt.\%. Previous research employed the use of short jute fibers as reinforcements in polypropylene matrix, samples were produced via a screw extrusion process. The result showed that samples containing $20 \mathrm{wt}$. \% jute fiber had higher mechanical properties than other samples with fire retardants (such as $\mathrm{MgO}$, $\mathrm{Al}_{2} \mathrm{O}_{3}$, and $\left.\mathrm{H}_{3} \mathrm{PO}_{4}\right)$ [14]. A study on the effect of chemical treatment on the properties of jute fiber/low-density polyethylene by [15] proved that the use of alkali/silane treatment gave the best enhancement in flexural, tensile, and impacts strengths when matched with the untreated ones. The use of oil palm fibers has also been investigated by [16], where the addition of oil palm empty fruit bunch to unplasticized polyvinyl chloride showed an increase in flexural modulus with a corresponding decrease in the impact and flexural strength. Hybridization of oil palm fiber with glass fiber [17-19], kaolinite [20], and sisal fiber [21-23] has been investigated to improve the properties and performance of polymer matrix in previous research. In the present study, the influence of blending jute and OPPF fibers (treated and untreated) with high-density polyethylene (HDPE). This was done to determine the effect of chemical treatment and fiber loading on the mechanical properties of the resultant HDPE/JF/OPPF hybrid composites.

\section{Materials and Methods}

The materials used for this research include: oil palm pressed fruit fiber (OPPFF), which was extracted from oil pressed palm fruit collected from Bolorunduro, Ondo State, South Western part of Nigeria. Jute fiber (JF) was obtained from a local store in Akure also in the Southwestern part of Nigeria. Sodium hydroxide $(\mathrm{NaOH})$, and releasing agent 
were purchased from Pascal Chemical Ltd., Akure, Ondo State, Nigeria. High-density polyethylene (HDPE) pellets with a melt flow index (MFI) of $8 \mathrm{~g} / 10 \mathrm{~min}$ (XZ 89712-00 RD 10140182040), a molecular weight of $168,000 \mathrm{~g} \mathrm{~mol}^{-1}$, a melting point of $130{ }^{\circ} \mathrm{C}$, and a density of $0.954 \mathrm{~g} \mathrm{~cm}^{-3}$ was supplied by DOW Chemicals, South Africa [24].

OPPFF was extracted by pouring the oil palm fruit into a screw press machine at elevated temperature for $1 \mathrm{~h}$. This was done to melt the palm oil to a considerable extent and the oil was further removed via washing in water leaving behind the palm kernel shell and OPPF fiber. The palm kernel shell and OPPF fibers were collected using a sieve and the fiber was detached from the shell thereafter. The OPPF fibers were oven-dried at $60{ }^{\circ} \mathrm{C}$ in an air blast oven for $4 \mathrm{~h}$ followed by treating with $1 \mathrm{M} \mathrm{NaOH}$ at $50^{\circ} \mathrm{C}$ for $4 \mathrm{~h}$ in a water bath shaker. The treated fibers were rinsed with distilled water, after which they were oven-dried again at $80^{\circ} \mathrm{C}$ (a temperature below the fiber's degradation temperature) for $6 \mathrm{~h}$ to ensure the complete removal of moisture. Similar to OPPF fiber, untreated jute fibers were also oven-dried at $60^{\circ} \mathrm{C}$ for $4 \mathrm{~h}$ while the Jute fibers were treated by soaking them in $1.3 \mathrm{M} \mathrm{NaOH}$ at $26^{\circ} \mathrm{C}$ for $12 \mathrm{~h}$, they were thereafter rinsed with distilled water and oven-dried at $80^{\circ} \mathrm{C}$ for $6 \mathrm{~h}$. The jute and OPPF fibers were trimmed to a length of $2.5 \mathrm{~mm}$.

The chemical constituents (lignin, cellulose, and hemicellulose) of the JF and OPPFF were obtained using the neutral detergent and acid detergent methods. The test was carried out in concert with Van Soest and Wine [25] and Georing and Vansoest [26] to estimate the weight fraction of acid detergent fiber and neutral detergent fiber which was used to determine the percentage of lignin, cellulose, and hemicellulose of jute and OPPF fibers.

The composites were developed using the compression molding technique by random dispersion of jute and OPPF fibers in the polypropylene matrix. Predetermined proportions as shown in Table 1 of OPPFF and JF were mixed with HDPE matrix in a tumbler mixer for $30 \mathrm{~min}$ to obtain a homogeneous mixture. A rectangular mold of dimension $150 \mathrm{~mm} \times 100 \mathrm{~mm} \times 4 \mathrm{~mm}$. was filled up with mixed materials. Compression was done at $130{ }^{\circ} \mathrm{C}$ for $12 \mathrm{~min}$ under an applied pressure of $0.2 \mathrm{kPa}$ with the aid of a compression molding machine to develop standard samples of tensile and flexural test specimens. The test samples were designated as shown in Table 1. Degassing of the composite samples was carried out at a specific time after the introduction of the composite sample into the compression molding machine, to remove entrapped gases. The developed samples were allowed to cool at room temperature.

Table 1. Mix Ratio for HDPE/OPPF Fiber/Jute fiber (JF) Composites.

\begin{tabular}{cccc}
\hline Sample Designation & HDPE (wt.\%) & OPPF Fiber (wt.\%) & JF (wt.\%) \\
\hline Control (A) & 100 & - & - \\
B & 80 & 8 & 12 \\
C & 80 & 12 & 8 \\
D & 80 & - & 20 \\
E & 80 & 20 & - \\
\hline
\end{tabular}

The Scanning Electron Microscope (SEM) (JOEL JSM-7600F) attached with Energy Dispersive X-ray Spectrometer was used to characterize the surface and fracture morphology of the fibers and the developed composites respectively. The fibers were coated with platinum and the samples were placed in a high-pressure chamber. The secondary electrons were amplified due to the charge neutralization around the sample caused by the high-pressure regions. The morphology of the fractured surface was carried out to investigate the interfacial adhesion between the HDPE matrix and the fibers used.

The tensile test was carried out to evaluate the ultimate tensile strength, tensile modulus, and tensile strain of the produced composite samples using a universal tester (Instron 3369 model) following ASTM D636 [27] at room temperature $\left(25^{\circ} \mathrm{C}\right)$, strain rate of $5 \mathrm{~mm} / \mathrm{min}$, and relative humidity of $40 \%$ with a load cell of $10 \mathrm{~kg}$. Three identical samples were evaluated, and their average was computed and used as the representative value for each composition. Flexural properties such as ultimate flexural strength, flexural 
modulus, and flexural strain of the composites produced were carried out with the aid of testometric universal testing machine following ASTM D790 [28]. The samples were placed under three-point bend fixtures at a rate of $10 \mathrm{~mm} / \mathrm{min}$. Three similar samples were subjected to flexural test and their average was adopted as the representative value for each weight fraction.

\section{Results and Discussion}

\subsection{Compositional Analysis of the Fibers}

Table 2 shows the chemical composition of the fibers. It was observed that there was a decrease in the percentage of lignin and hemicellulose of the treated fibers when compared with the untreated ones, while there was an increase in the percentage of cellulose for both jute and OPPF fibers. Previous research [29] affirmed the fact that the presence of lignin and hemicellulose in natural fibers causes poor interfacial adhesion which emanates from their hydrophilic nature. They also lead to fiber degradation which can cause the loss of mechanical properties while in service. In this study, alkali treatment improved the adhesion between the reinforcing phase and matrix phase by enhancing the interaction between the two phases [30]. This treatment selectively eliminated the lignin (the unreactive part of natural fiber) and hemicellulose in both Jute and OPPF fibers and also improved the surface roughness of both fibers as highlighted in Figures 3 and 4. Hemicellulose and lignin were noted to be $21.47 \%$ and $13.3 \%$ for untreated jute fiber while $18.34 \%$ and $10.9 \%$ were recorded after treatment. The same trend was observed for OPPF fiber where hemicellulose and lignin also reduced after chemical treatment. In addition, the cellulose contents of jute and OPPF fibers were observed to have increased drastically due to this treatment. This could also lead to improved adhesion because the amount of modified cellulose present at the fiber surface has increased [31,32].

Table 2. Compositional Analysis of the Fibers.

\begin{tabular}{ccccc}
\hline & Cellulose (\%) & Hemicellulose (\%) & Lignin (\%) & Others (\%) \\
\hline Untreated jute fiber & 58.47 & 21.47 & 13.3 & 6.76 \\
Treated jute fiber & 66.28 & 18.34 & 10.9 & 4.48 \\
Untreated OPPF fiber & 49.43 & 23.78 & 19.43 & 7.36 \\
Treated OPPF fiber & 56.72 & 19.74 & 17.23 & 6.31 \\
\hline
\end{tabular}

\subsection{Energy Dispersive X-ray (EDX) Spectroscopic Analysis of Jute and OPPF Fibers}

The EDX spectroscopic analyses of the fibers were carried out to investigate the extent of purification of the fibers due to the $\mathrm{NaOH}$ treatments given to the fibers. Figures 1 and 2 present the elemental composition of untreated and treated jute fiber and OPPF fiber respectively.
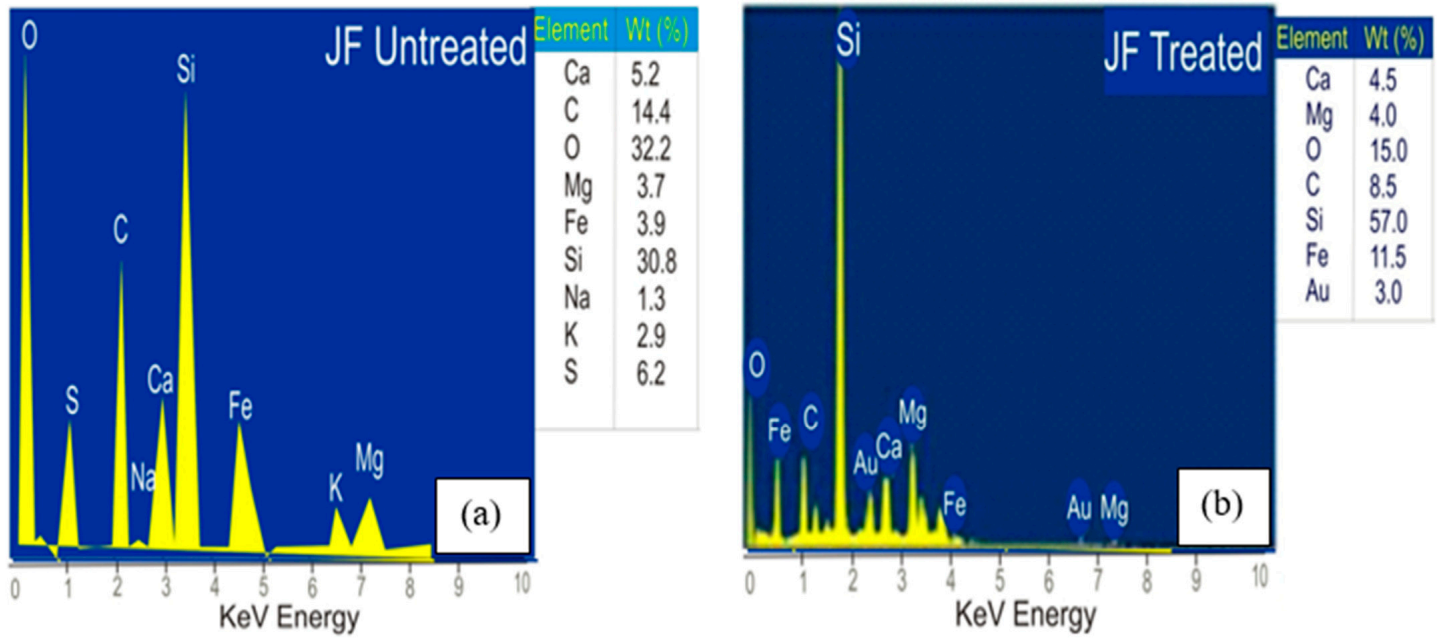

Figure 1. Elemental Composition of (a) Untreated Jute Fiber and (b) Treated Jute Fiber. 

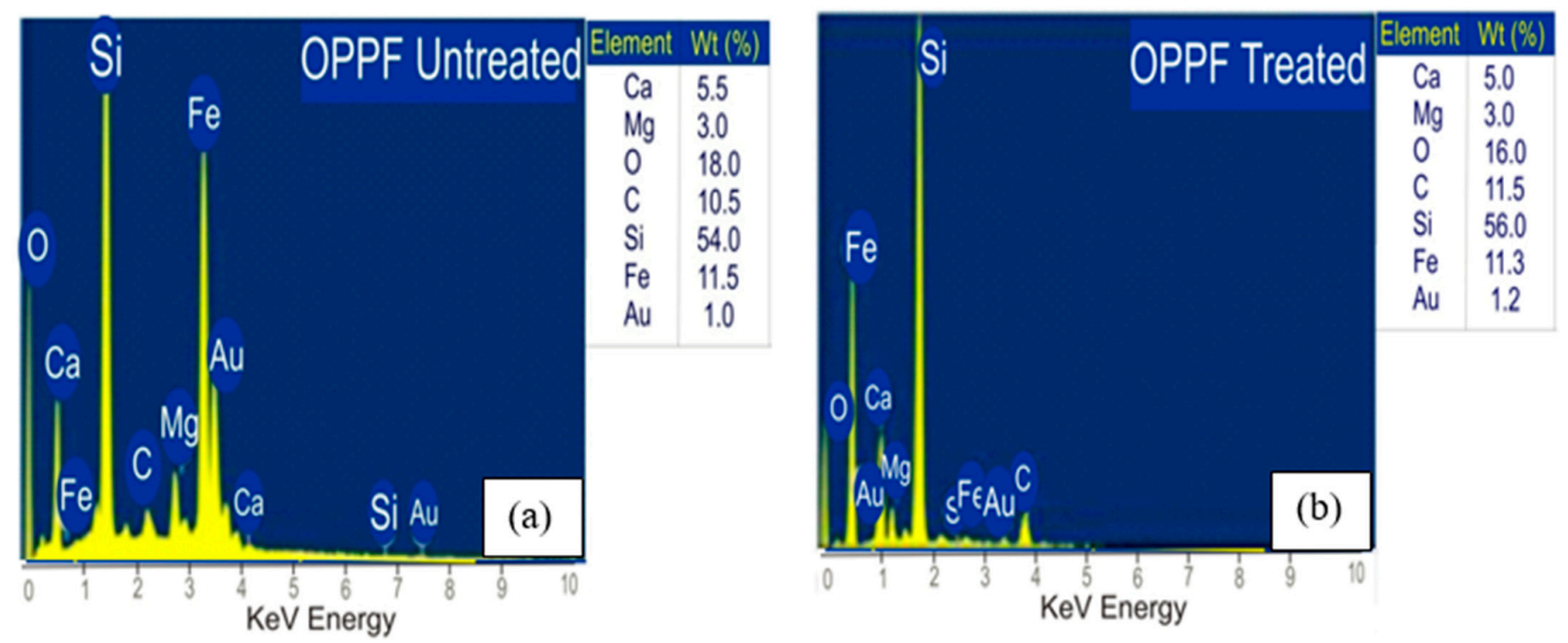

Figure 2. Elemental composition of (a) untreated OPPF fiber and (b) treated OPPF Fiber.

Figures 1 and 2 revealed the presence of elements such as silicon, oxygen, iron, calcium, carbon, gold, and magnesium. Potassium, sodium, and sulfur were also discovered in the untreated jute fiber, which are regarded as impurities. The alkaline treatment given to the fiber caused the removal of these impurities and the presence of gold was discovered in the treated jute along with both treated and untreated OPPF fibers. The EDX analysis also showed the presence of silica in the form of silicon and oxygen. Silica is known to be a hard ceramics material that improves the strength of a polymer matrix [33,34].

\subsection{Surface Morphology of the Jute and OPPF Fibers}

Figures $3 \mathrm{a}$ and $4 \mathrm{a}$ show the presence of impurities such as lignin and hemicelluloses on the surface of the fibers with respective flaky and cloudy like appearances which are gums when compared to Figures $3 b$ and $4 b$ that shows fibers with rough and exposed surface; the impurities have been removed as a result of the chemical treatment given to the fibers [35]. The reduction in the amount of lignin and hemicellulose brings about an increase in the percentage of cellulose at the fiber surface which prompts improved adhesion as confirmed by [30,33]. Additionally, the number and diameter of the treated fibers vary as is observed between Figures $3 b$ and $4 b$.
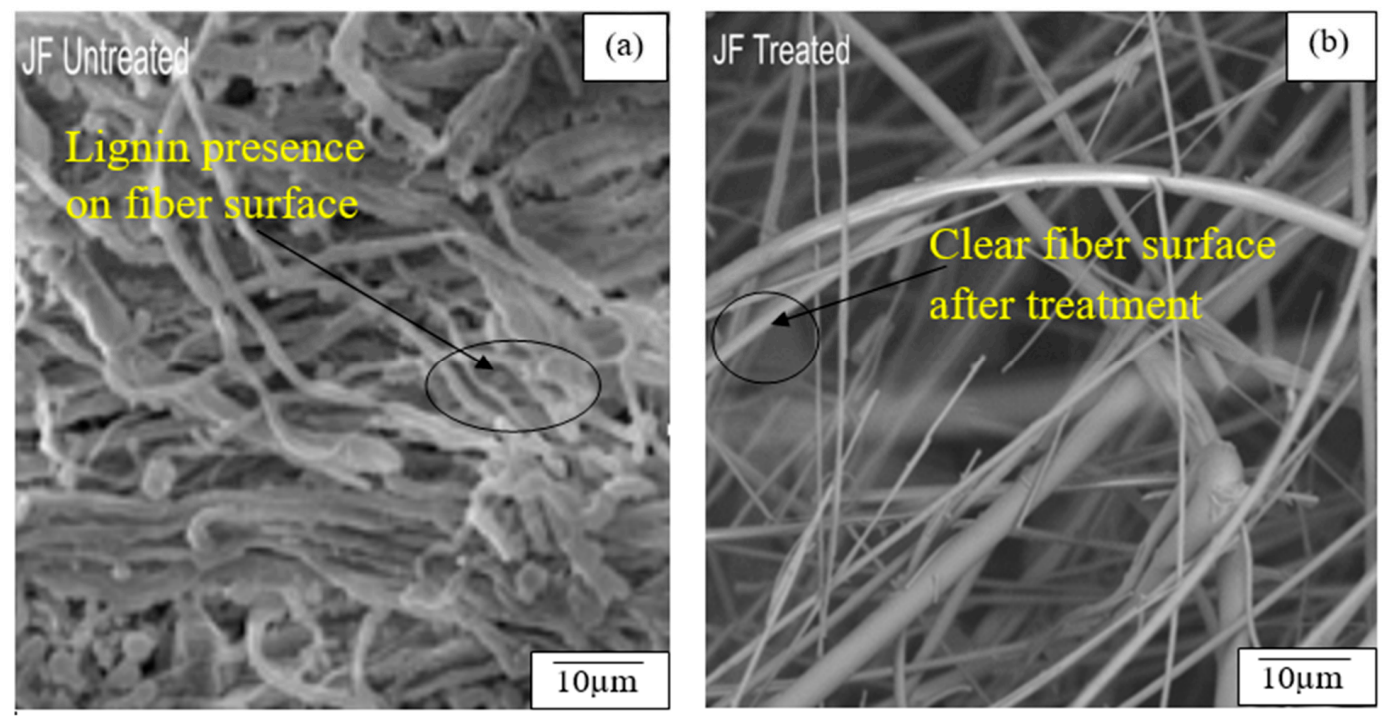

Figure 3. SEM Image of (a) Untreated Jute Fiber (b) Treated Jute Fiber. 

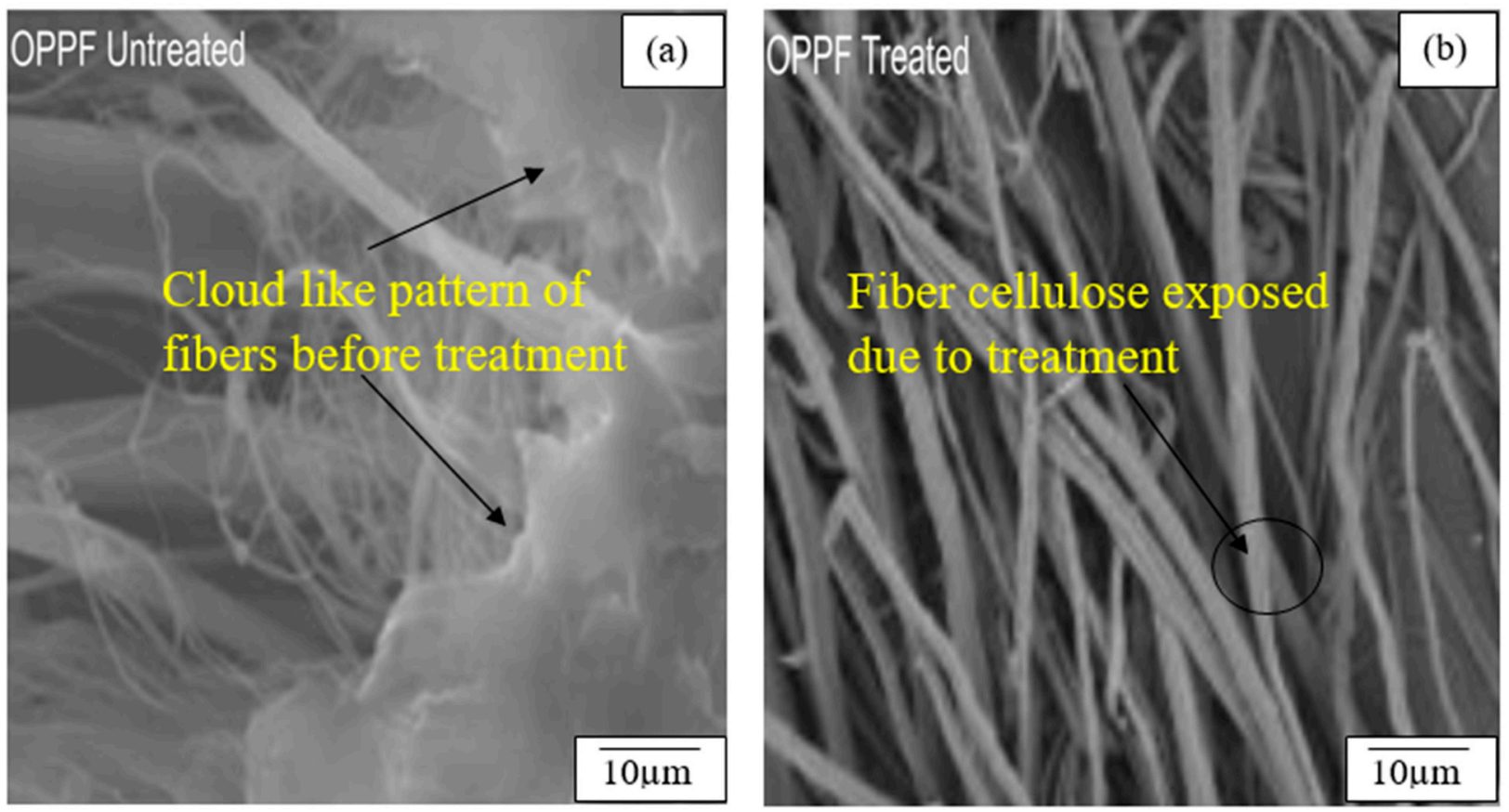

Figure 4. SEM Image of (a) Untreated OPPF Fiber (b) Treated OPPF Fiber.

\subsection{Microstructural Examination of the Developed Composites}

The SEM images in Figure 4. Revealed the microstructural features of the developed hybrid composites. From Figure 5a the presence of cavities was observed in the hybrid composites. These features may result in the reduction of tensile and flexural properties of the samples developed [36]. The SEM image of HDPE/ / $20 \mathrm{wt}$ \% JF single reinforcement composite shown in Figure $5 b$ displayed the minimum amount of cavities, leading to efficient stress transfer from the matrix to the fibers. Therefore, the good adhesion between the fiber and the matrix observed in this study justified the good mechanical properties noticed in this composite [37]. Sample containing $12 \mathrm{wt}$ \% OPPF fiber was characterized with high level of cavities which leads to a reduction in its mechanical properties [38]. Additionally, lower properties observed may be linked to the inherent properties of OPPF fiber. This is determined by the fiber origin and the extraction process tends to affect the mechanical properties of the developed composites.
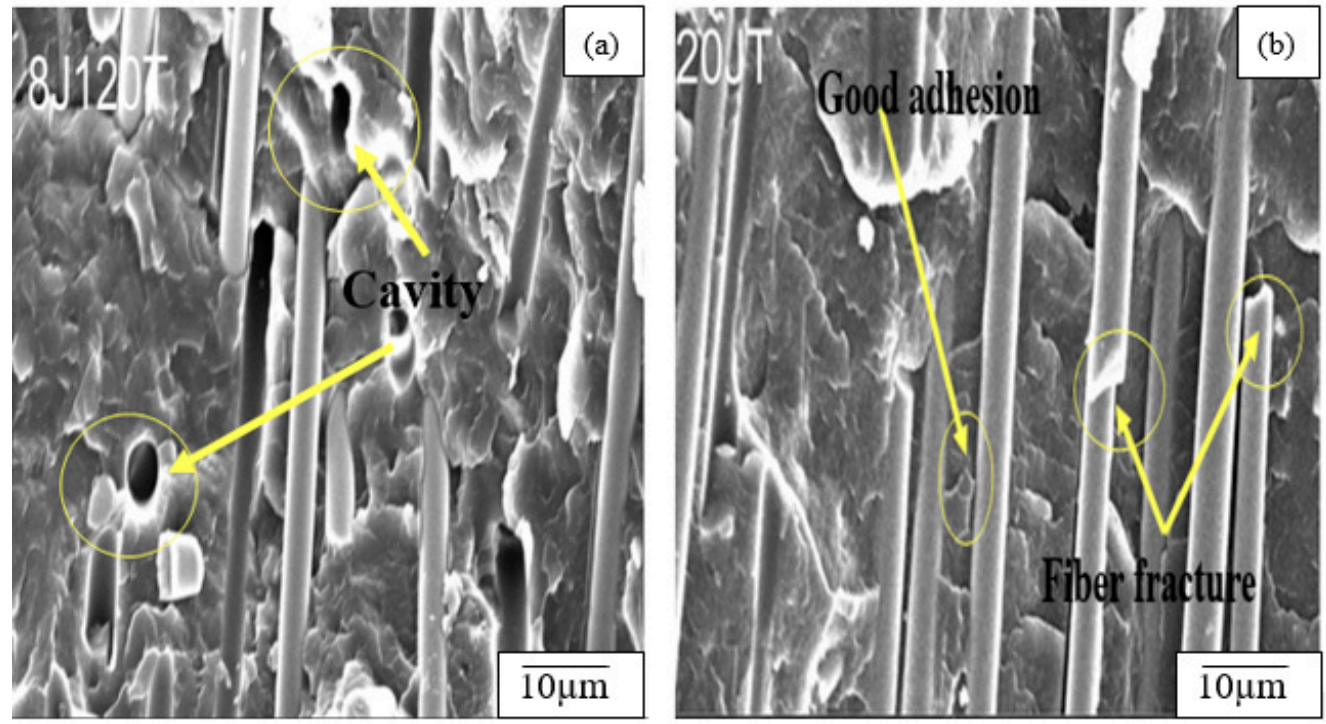

Figure 5. SEM image of (a) HDPE/12 wt.\% OPPFF/8 wt.\% JF Hybrid Composites (Sample B); (b) HDPE/20 wt.\% OPPFF Composite (Sample E). 


\subsection{Tensile Properties of HDPE/Jute Fiber/OPPF Fiber Composite}

3.5.1. Ultimate Tensile Strength (UTS)

The result of the UTS of the developed composites is as presented in Figure 6.

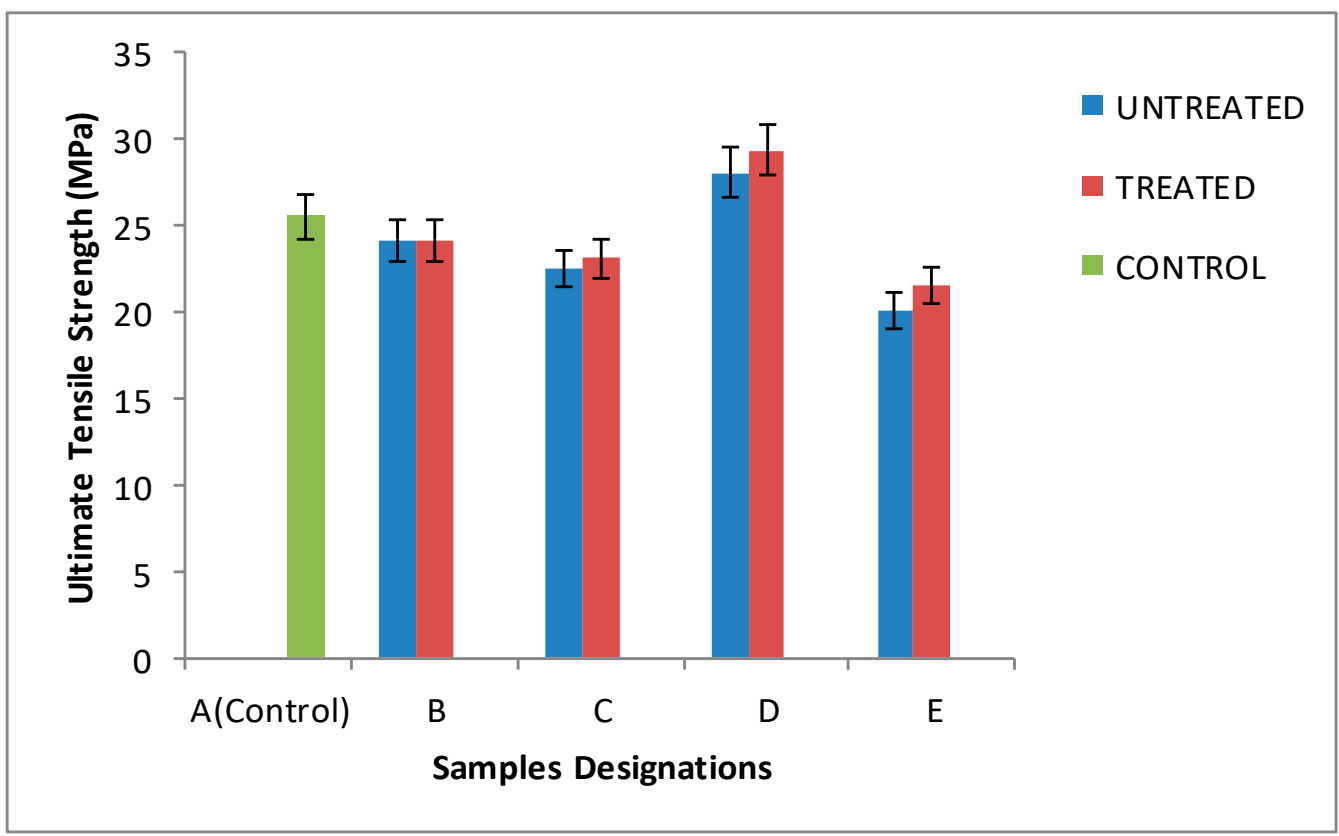

Figure 6. The ultimate tensile strength of the control sample and the developed composites.

From Figure 6, it was observed that the ultimate tensile strength for both the treated and untreated samples followed the same trend. Initially, there was a consistent decrease in the hybrid composites and OPPF fiber-reinforced composite (samples B and C; and sample E respectively) while an increase was recorded for sample $D$ when compared to the control sample A. The decrease in those samples may be attributed to the increase in the OPPF fiber in the matrix. Additionally, from the SEM images in Figure 5, it was observed that samples with more OPPF fiber contain more cavities. The reduction in the tensile strength observed is in agreement with the work of [8]. Similarly, hybridization of oil palm and sisal fiber as reinforcement in rubber composites was studied by [39,40], the authors examined the effect of fiber ratio, fiber loading, and surface modifications on the mechanical performance of oil palm/sisal rubber composites. The tensile properties were observed to be dependent on fiber loading. Due to the high tensile strength of sisal fibers, samples with higher content of sisal fibers and lower oil palm fibers had improved tensile strength than those with lower sisal fiber and a higher percentage of oil palm fibers. Jute as a single reinforcement gave improved properties and has the optimum strength in the developed composite (sample D) with values of 28.09 MPa and 29.34 MPa for untreated and treated samples respectively. This is about 9.98\% (2.55 MPa) and $14.87 \%(3.80 \mathrm{MPa})$ enhancement in the property when compared with the control sample (HDPE) which has an ultimate tensile strength of $25.54 \mathrm{MPa}$. The treated samples have better strength than their untreated counterpart because the alkaline treatment is usually known to enhance the tensile properties of natural fiber, by reducing the impurities level such as hemicellulose and lignin thereby increases the adhesion property of the fiber [24,41,42].

\subsubsection{Tensile Modulus}

As shown in Figure 7, it was observed that the tensile modulus for both the treated and untreated samples follows the same trend. The tensile modulus of the single jute reinforced composite increases at sample $\mathrm{D}$ when compared to the control. This improvement is about $12.77 \%$ and $14.15 \%$ for untreated and treated samples respectively. A little drop of the tensile moduli of the hybrid samples and OPPF fiber reinforced composites were observed 
in samples B and C, and sample E respectively. Sample D (a jute fiber-reinforced composite) has the highest value of $1261.85 \mathrm{MPa}$ and 1277.26 MPa for untreated and treated fibers respectively, while Sample E (an OPPF fiber-reinforced composite) has the lowest tensile modulus of $1142.12 \mathrm{MPa}$ and $1182.59 \mathrm{MPa}$ for untreated and treated fibers, respectively. The reduction in the tensile modulus may be linked to the presence of cavities and fiber entanglement as revealed by the microstructures of these samples in Figure $5 a, b$ which hinders effective stress transfer between the fiber and the matrix. The research work of [43] showed that by increasing the fiber weight fraction of jute to $22 \mathrm{wt} . \%$, after a $15 \%$ decrease in tensile modulus experienced when $11 \mathrm{wt} . \%$ fiber weight fraction of jute fiber was used, the tensile modulus improved by $71 \%$ compared to those of the control HDPE sample. The decrease in the tensile strength and modulus of sample E may be due to the presence of cavities, and poor interfacial adhesion between the fiber and the matrix $[7,19,44]$.

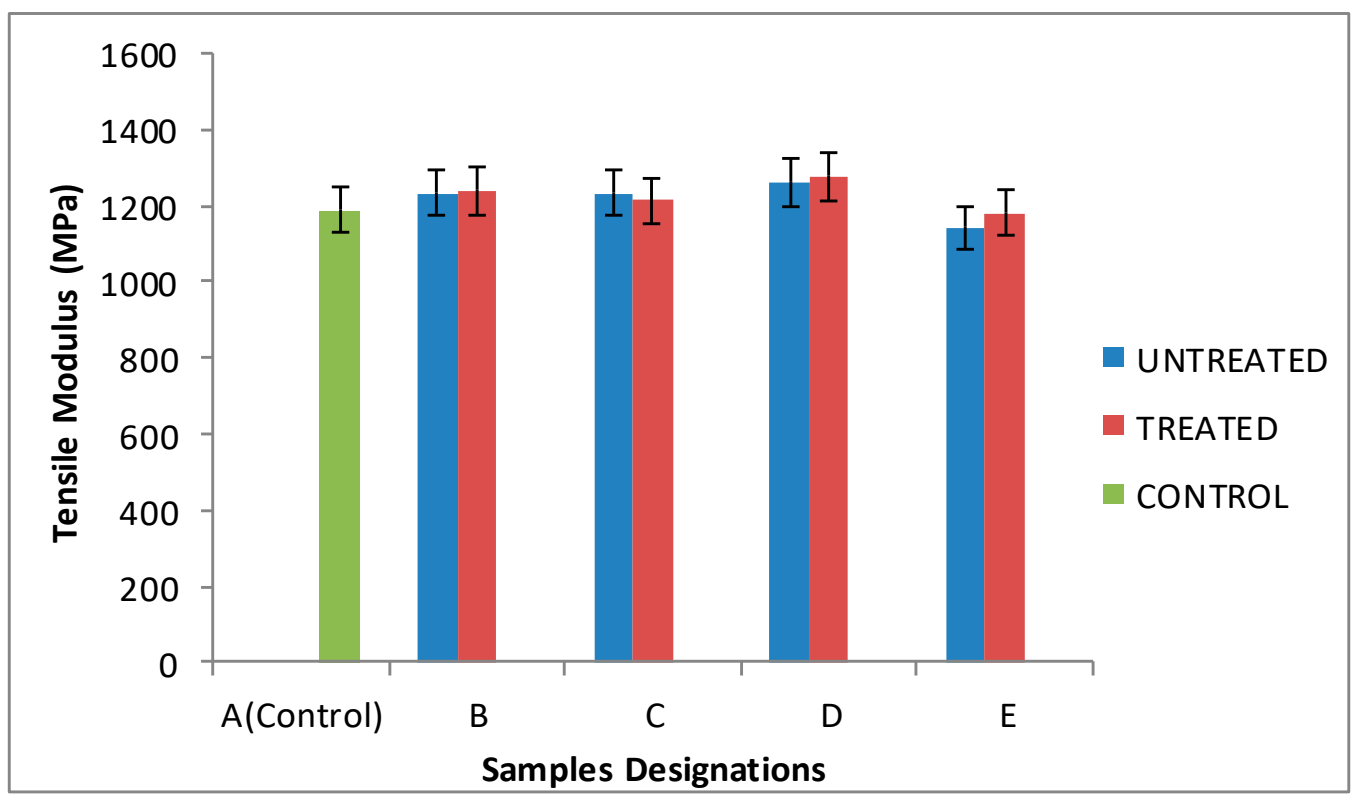

Figure 7. The tensile modulus of the control sample and the developed composites.

\subsection{Flexural Properties of the Composite and the Control Sample}

\subsubsection{Flexural Strength at Peak}

It can be observed from Figure 8 that for the hybrid composite, as the jute fiber weight fraction decreases and OPPF fiber weight fraction increases, the flexural strength decreases, as seen in the OPPF fiber single reinforced HDPE matrix composite, the strength exhibited is low as compared to sample D (JF single reinforced HDPE matrix Composite) that shows the highest enhancement value. This enhancement in the flexural strength occurred at the single reinforced jute fiber contents with the value of $34.18 \mathrm{MPa}$ and $39.74 \mathrm{MPa}$, which was enhanced by $3 \%$ and $19 \%$ for untreated and treated respectively compared to that of the control. This was in concert with the study of [45] who reported a reduction in tensile and flexural strength as the weight content of randomly dispersed oil palm fiber increases from 0-20 wt.\%. 


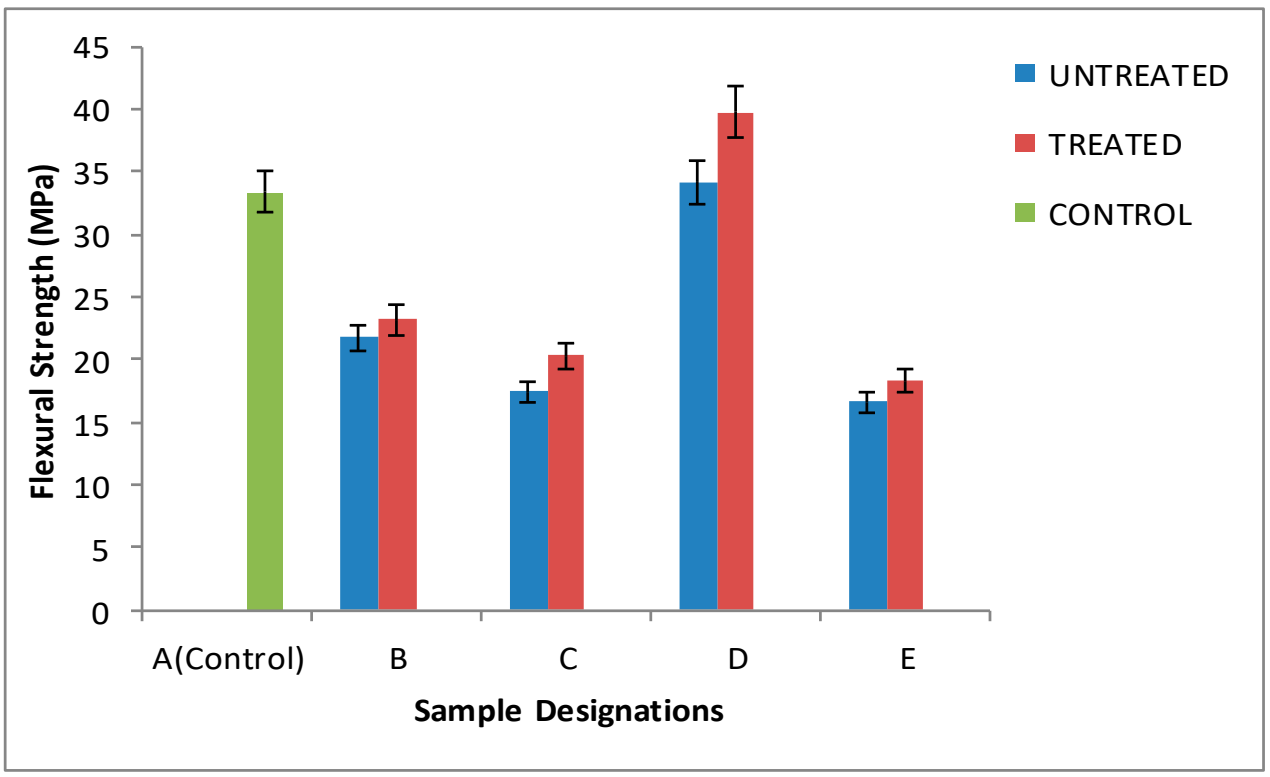

Figure 8. The flexural strength of the control sample and the developed composites.

\subsubsection{Flexural Modulus}

The flexural modulus trend as shown in Figure 9 was similar to what was obtained in Figure 8. The flexural modulus reduces with an increase in the reinforcement weight fraction progressively. The addition of JF as a single reinforcement gave improved modulus. Sample with jute fiber only has the highest flexural modulus of $1285.15 \mathrm{MPa}$ and $1395.38 \mathrm{MPa}$ which amounts to $7.32 \%$ and $16.53 \%$ enhancement in its property for the untreated and treated sample respectively. This can be attributed to the good inherent properties of the jute fiber as stated in [46,47]. From Figures 8 and 9, it became apparent that the hybrid composites did not give good flexural strength and modulus as compared to that of jute fiber. However, the presence of jute fiber improved flexural modulus when coupled with OPPF fiber. Higher values were obtained for the hybrid composites when the flexural modulus was matched with that of the single OPPF reinforced composite. This agrees with the findings of [48].

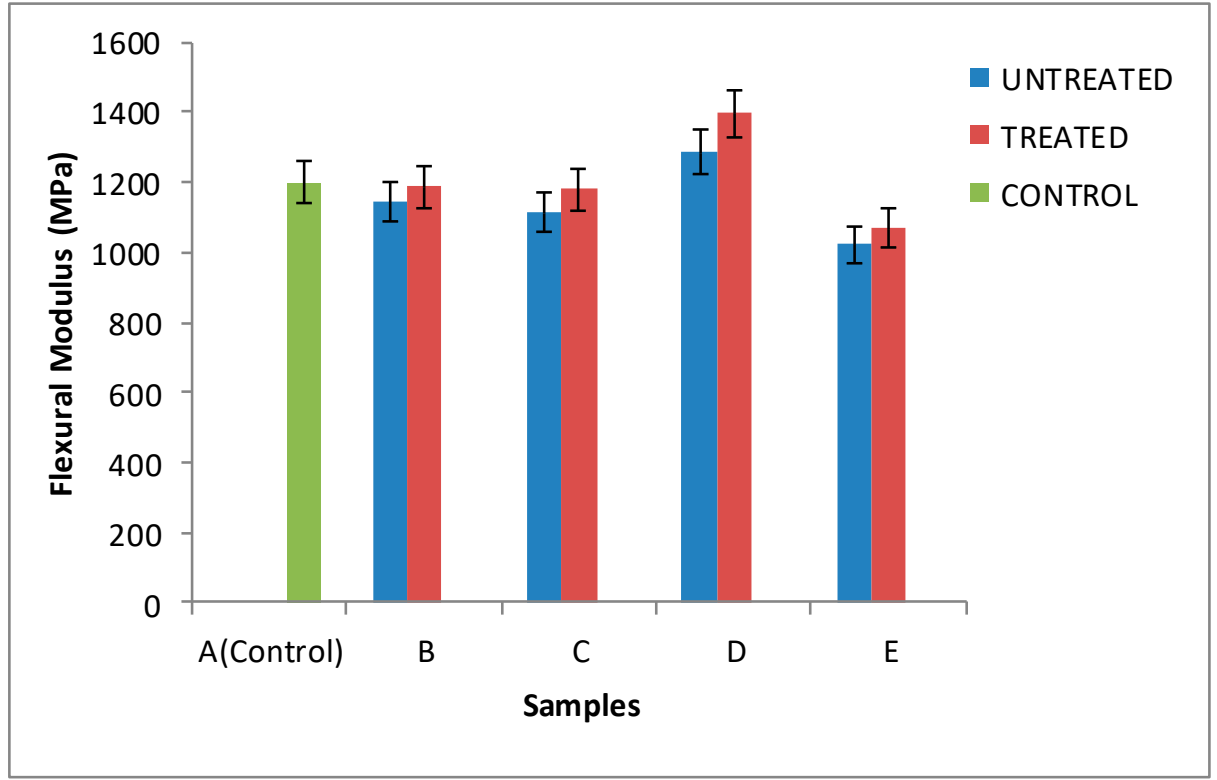

Figure 9. The flexural modulus of the control sample and the developed composites. 


\section{Conclusions}

HDPE matrix composites reinforced with Jute and OPPF fibers were successfully produced using the compression molding technique, they were probed for tensile and mechanical properties. Afterward, the following conclusions were drawn.

1. Alkaline treatment of the fibers was instrumental in the removal of hemicellulose and lignin contents present in the fiber which was demonstrated by the improved properties observed in treated fibers reinforced HDPE as compared to the untreated ones.

2. Treated $20 \mathrm{wt} . \%$ jute fiber reinforced HDPE came out with the best tensile and flexural properties, signifying the reinforcing efficiency of jute fiber while the hybrid composites showed intermediate property particularly $8 \mathrm{wt} . \% \mathrm{JF}$ and $12 \mathrm{wt} . \%$ OPPFF.

3. The research showed that as the weight fraction of OPPF fiber increases in the mix, microstructural features such as a cavity, fiber fracture, and fiber touching were more prominent. This led to a reduction in flexural and tensile properties while the increase in jute fiber resulted in improved adhesion and reduced cavities and fiber fracture.

Author Contributions: Conceptualization, O.O.D. and O.A.B.; methodology, O.O.D. and O.A.B.; software, O.A.B.; validation, O.A.B. and S.O.S.; formal analysis, O.A.B.; investigation, O.O.D.; resources, O.A.B.; data curation, O.O.D., O.A.B., A.A.A., S.O.S., and I.O.O.; writing-original draft preparation, O.O.D., O.A.B., A.A.A., S.O.S., I.O.O., and E.T.A.; writing-review and editing, I.O.O.; visualization, O.O.D.; supervision, O.A.B.; project administration, O.A.B.; funding acquisition, O.O.D., O.A.B., A.A.A., S.O.S., I.O.O., and E.T.A. All authors have read and agreed to the published version of the manuscript.

Funding: The APC was funded by University of Johannesburg and Pan African University of Life Sciences Institute, Ibadan.

Institutional Review Board Statement: Not applicable.

Informed Consent Statement: Not applicable.

Data Availability Statement: The data presented in this study are available within the manuscript.

Acknowledgments: Authors appreciate the following Institution: The Federal University of Technology, Akure, Landmark University SDGs-17 Research Group, and University of Johannesburg for their support.

Conflicts of Interest: The authors declare no conflict of interest.

\section{References}

1. Gibson, F.R. Principle of Composite Material Mechanics; CRC Press: Boca Raton, FL, USA, 2011; Volume 3, pp. 7-14.

2. Bisht, S.; Lamba, N. Use of Simulation Driven Design for New Product Development. Int. J. Emerg. Technol. $2014,5,201-205$.

3. Akbarov, S.D.; Guz, A.N. Mechanics of Curved Composites; Kluwer Academic Publishers: Dordrecht, The Netherlands, $2000 ;$ p. 446.

4. Mochane, M.J.; Mokhena, T.C.; Mokhothu, T.H.; Mtibe, A.; Sadiku, E.R.; Ray, S.S.; Ibrahim, I.D.; Daramola, O.O. Recent progress on natural fiber hybrid composites for advanced applications: A review. Express Polym. Lett. 2019, 13, 159-198. [CrossRef]

5. Oladele, I.O.; Ayanleye, O.T.; Adediran, A.A.; Makinde-Isola, B.A.; Taiwo, A.S.; Akinlabi, E.T. Characterization of Wear and Physical Properties of Pawpaw-Glass Fiber Hybrid Reinforced Epoxy Composites for Structural Application. Fibers 2020, 8, 44. [CrossRef]

6. Ahmad, F.; Choi, H.S.; Park, M.K. A review: Natural fiber composites selection in view of mechanical, light weight, and economic properties. Macromol. Mater. Eng. 2015, 300, 10-24. [CrossRef]

7. Alamri, H.; Low, I.M. Effect of water absorption on the mechanical properties of n-SiC filled recycled cellulose fibre reinforced epoxy eco-nanocomposites. Polym. Test. 2012, 31, 810-818. [CrossRef]

8. Jawaid, M.; Khalil, H.P.S.A.; Bakar, A.A. Mechanical Performance of Oil Palm Empty Fruit Bunches/Jute Fibers Reinforced Epoxy Hybrid Composites. Mater. Sci. Eng. A 2010, 527, 7944-7949. [CrossRef]

9. Oladele, I.O.; Oladejo, M.O.; Adediran, A.A.; Makinde-Isola, B.A.; Owa, A.F.; Akinlabi, E.T. Influence of designated properties on the characteristics of dombeya buettneri fiber/graphite hybrid reinforced polypropylene composites. Sci. Rep. 2020, 10, 1-13. [CrossRef]

10. Dalbehera, S.; Acharya, S.K. Study on Mechanical Properties of Natural Fiber Reinforced Woven Jute-Glass Hybrid Epoxy Composites. Adv. Polym. Sci. Technol. 2014, 4, 1-6.

11. Debiprasad, G.; Kousik, D.; Palash, P.; Subhankar, M. Jute Composites as Wood Substitute. Int. J. Text. Sci. 2012, 1, 84-93. 
12. Shahbandeh, M. Palm Oil: Global Production Volume 2012/13-2020/21. Available online: https://www.statista.com/statistics/ 613471/palm-oil-production-volume-worldwide (accessed on 27 May 2021).

13. Singh, E.; Deepak, D.; Aggarwal, L.; Gupta, V.K. Fabrication and Characterization of Jute Fiber-Reinforced-Recycled Polyethylene Composites. In Proceedings of the International Conference on Research and Innovations in Mechanical Engineering; Lecture Notes in Mechanical Engineering; Khangura, S., Singh, P., Singh, H., Brar, G., Eds.; Springer: New Delhi, India, 2014. [CrossRef]

14. Chestee, S.S.; Poddar, P.; Sheel, T.K.; Rashid, M.M.; Khan, R.A.; Chowdhury, A.M.S. Short Jute Fiber Reinforced Polypropylene Composites: Effect of Nonhalogenated Fire Retardants. Adv. Chem. 2017, 2017, 1-8. [CrossRef]

15. Ovalı, S.; Sancak, E. Investigation of Mechanical Properties of Jute Fiber Reinforced Low Density Polyethylene Composites. J. Nat. Fibers 2020, 1-18. [CrossRef]

16. AbuBakar, A.; Hassan, A.; Mohd Yusof, A.F. Mechanical and Thermal Properties of Oil Palm Empty Fruit Bunch-Filled Unplasticized Poly (Vinyl Chloride) Composites. Polym. Polym. Compos. 2005, 13, 607-617.

17. Karina, M.; Onggo, H.; Abdullah, A.H.D.; Syampurwadi, A. Effect of oil palm empty fruit bunch fiber on the physical and mechanical properties of fiber glass reinforced polyester resin. J. Biol. Sci. 2008, 8, 101-106.

18. Wong, K.J.; Nirmal, U.; Lim, B.K. Impact behavior of short and continuous fiber-reinforced polyester composites. J. Reinf. Plast. Compos. 2010, 29, 3463-3474. [CrossRef]

19. Anuar, H.; Ahmad, S.H.; Rasid, R.; Daud, N.S.N. Tensile and impact properties of thermoplastic natural rubber reinforced short glass fiber and empty fruit bunch hybrid composites. Polym.-Plast. Technol. Eng. 2006, 45, 1059-1063. [CrossRef]

20. Amin, M.; Anuar, K.; Badri, H.K. Palm-based bio-composites hybridized with kaolinite. J. Appl. Polym. Sci. 2007, 105, 2488-2496. [CrossRef]

21. Jacob, M.; Varughese, K.T.; Thomas, S. Water sorption studies of hybrid biofiber-reinforced natural rubber biocomposites. Biomacromolecules 2005, 6, 2969-2979. [CrossRef]

22. Jacob, M.; Varughese, K.T.; Thomas, S. Dielectric characteristics of sisal-oil palm hybrid biofibre reinforced natural rubber biocomposites. J. Mater. Sci. 2006, 41, 5538-5547. [CrossRef]

23. Jacob, M.; Thomas, S.; Varughese, K.T. Biodegradability and Aging Studies of Hybrid Biofiber Reinforced Natural Rubber Biocomposites. J. Biobased Mater. Bioenergy 2007, 1, 118-126. [CrossRef]

24. Daramola, O.O.; Akinwekomi, A.D.; Adediran, A.A.; Akindote-White, O.; Sadiku, E.R. Mechanical Performance and Water Uptake Behaviour of Treated Bamboo Fibre-Reinforced High-Density Polyethylene Composites. Heliyon 2019, 5, e02028. [CrossRef]

25. Van Soest, P.J.; Wine, R.H. Determination of lignin and cellulose in Acid-Detergent fiber with permanganate. J. Assoc. Off. Agric. Chem. 1968, 51, 780-785. [CrossRef]

26. Georing, H.K.; Van Soest, P.J. Forage Fiber Analysis. USDA Agricultural Handbook; USDA ARS: Washington, DC, USA, 1970; Volume 397, pp. 1-12.

27. ASTM D636. Standard Test Method for Tensile Properties of Plastics; ASTM International: West Conshohocken, PA, USA, 2014.

28. ASTM D790. Standard Test Method for Flexural Properties of Unreinforced and Reinforced Plastics and Electrical Insulating Materials; ASTM International: West Conshohocken, PA, USA, 2017.

29. Benmansour, N.; Agoudjil, B.; Gherabli, A.; Abdelhak, K.; Boudenne, A. Thermal and mechanical performance of natural mortal reinforced with date palm fibers for use as insulating materials in building. Energy Build. 2014, 81, 98-104. [CrossRef]

30. Oladele, I.; Oghie, I.I.; Adediran, A.A.; Akinwekomi, A.; Adetula, Y.; Olayanju, T.M.A. Modified palm kernel shell fiber/particulate cassava peel hybrid reinforced epoxy composites. Results Mater. 2019, 5, 10053. [CrossRef]

31. Wang, H.; Memon, H.; Hassan, E.A.; Maih, M.S.; Ali, M.A. Effect of Jute Fiber Modification on the Mechanical Properties of Jute Fiber Composites. Materials 2019, 12, 1226. [CrossRef]

32. Mohammed, L.; Ansari, M.N.M.; Pua, G.; Jawaid, M.; Saiful, I.M. A Review on Natural Fibre Reinforced Polymer Composite and Its Applications. Int. J. Polym. Sci. 2015, 2015, 243947. [CrossRef]

33. Adediran, A.A.; Balogun, O.A.; Akinwande, A.A.; Adesina, O.S.; Olasoju, O.S. Influence of chemical treatment on the properties of cement-paper hybrid composites for ceiling board application. Heliyon 2020, 6, e04512. [CrossRef]

34. Daramola, O.O.; Oladele, I.O.; Adewuyi, B.O.; Sadiku, R.; Agwuncha, S.C. Influence of Submicron Agro Waste Silica Particles and Vinyl Acetate on Mechanical Properties of High-Density Polyethylene Matrix Composites. West Indian J. Eng. 2015, 38 , 96-107.

35. Yan, L.; Chouw, N.; Yuan, X. Improving the mechanical properties of natural fiber fabric reinforced epoxy composites by alkali treatment. J. Reinf. Plast. Compos. 2012, 31, 425-437. [CrossRef]

36. Jawaid, M.; Abdul Khalila, H.P.S.; Bakar, A.A.; Noorunnisa Khanam, P. Chemical resistance, void content and tensile properties of oil palm/jute fibre reinforced polymer hybrid composites. Mater. Des. 2011, 32, 1014-1019. [CrossRef]

37. Shanmugam, D.; Thiruchitrambalam, M. Influence of alkali treatment and layering pattern on the tensile and flexural properties of Palmyra palm leaf stalk fiber (PPLSF)/jute fiber polyester hybrid composites. Compos. Interfaces 2014, 21, 3-12. [CrossRef]

38. Bernal, C.R. Deformation and Fracture Behavior of Natural Fiber Reinforced Polypropylene. In Polyolefin Composites; John Wiley \& Sons: Hoboken, NJ, USA, 2008; Chapter 7; pp. 178-203.

39. Jacob, M.; Thomas, S.; Varughese, K.T. Natural rubber composites reinforced with sisal/oil palm hybrid fibers: Tensile and cure characteristics. J. Appl. Polym. Sci. 2004, 93, 2305-2312. [CrossRef]

40. Jacob, M.; Thomas, S.; Varughese, K.T. Mechanical properties of sisal/oil palm hybrid fiber reinforced natural rubber composites. Compos. Sci. Technol. 2004, 64, 955-965. [CrossRef] 
41. Obasi, H.C.; Iheaturu, N.C.; Onuoha, F.N.; Chike-Onyegbula, C.O.; Akanbi, M.N.; Eze, V.O. Influence of alkali treatment and fiber content on the properties of oil palm press fiber reinforced epoxy biocomposites. Am. J. Eng. Res. 2014, 3, 117-123.

42. Hamma, A.; Kaci, M.; Ishak, Z.A.M.; Pegoretti, A. Starch-grafted-polypropylene/kenaf fibres composites. Part 1: Mechanical performances and viscoelastic behavior. Compos. Part A Appl. Sci. Manuf. 2014, 56, 328-335. [CrossRef]

43. Elbadry, E.A.; Aly-Hassan, M.S.; Hamada, H. Mechanical Properties of Natural Jute Fabric/Jute Mat Fiber Reinforced Polymer Matrix Hybrid Composites. Adv. Mech. Eng. 2012, 4, 354547. [CrossRef]

44. Mohd, N.N.; Khalina, A.; Sapuan, S.M.; Dayang, A.H.; Rahmah, M.; Hanafee, Z. A Review: Fibres, Polymer Matrices and Composites. Pertanika J. Sci. Technol. 2017, 25, 1085-1102.

45. Yusoff, M.Z.M.; Sapuan, S.M.; Ismail, N.; Wirawan, R. Mechanical Properties of Short Random Oil Palm Fibre Reinforced Epoxy Composites. Sains Malays. 2010, 39, 87-92.

46. Selver, E.; Ucar, N.; Gulmez, T. Effect of Stacking Sequence on Tensile, Flexural and Thermomechanical Properties of Hybrid Flax/Glass and Jute/Glass Thermoset Composites. J. Ind. Text. 2018, 48, 494-520. [CrossRef]

47. Swain, P.T.R.; Biswas, S. Influence of Fiber Surface Treatments on Physico-Mechanical Behaviour of Jute/Epoxy Composites Impregnated with Aluminium Oxide Filler. J. Compos. Mater. 2017, 51, 3909-3922. [CrossRef]

48. Jawaid, M.; Abdul Khalila, H.P.S.; Bakar, A.A. Tensile and flexural properties of oil palm-woven jute fibers based epoxy composites. Mater. Sci. Eng. A 2011, 528, 5190-5195. [CrossRef] 